this, the Association of Clinical Pathologists has devoted one of its well-known broadsheets to the subject, ${ }^{1}$ commissioning Professor David Gee of Leeds to compress into a few pages a most useful résumé of what needs to be done by a pathologist, police surgeon, or indeed any doctor when the circumstances dictate.

Because of the decay, identity is of paramount importance. In fact, in those few cases where foul play has occurred there may well have been a deliberate intention to conceal the body long enough for putrefaction to make identification difficult or impossible.

Examination of the remains at the place of death is always preferable, as the experienced medical eye can often relate the condition of the body to its environment and come to a quick conclusion, such as the presence of a faulty heating appliance causing asphyxia or gas poisoning. If the scene cannot be visited, then the body should at least be seen with the clothes in place; this examination may well explain otherwise dubious marks on the skin of the neck, if constriction by collars has to be distinguished from blurred strangulation marks.

Where time of death is important-and it often is paramount in the minds of police officers, who have a touching faith in the accuracy of medical opinion-then the stage of insect infestation and the condition of vegetation under the body may be vital. The actual degree of decomposition is an uncertain guide to the interval since death. Errors of several hundred per cent can be made by the most experienced pathologist. Not only does the environment change in an unpredictable way, but two persons in exactly the same surroundings may show gross variation in the degree of putrefaction, even if they are lying side by side. Reduction of the body to virtually a skeleton may occur in as little as three weeks, given hot weather and abundant insect life. At the other extreme, mummification or the formation of adipocere may allow the deceased to be recognisable after a year or more.

Bodies recovered from water form the most common source of decomposed remains and provide some of the most difficult problems. With the maxim that "All bodies from water need not have drowned" firmly in mind, the pathologist may find that the problem of the cause of death may be insuperable. Determining this is difficult enough in a fresh corpse, but often the only honest answer in a putrefied cadaver is "unascertainable." Even here, valuable negative evidence may be found, if sought for diligently. The identity as well as the absence of injuries or of natural disease may be of considerable help to the police and coroner, if the temptation to do as little as possible with nostrils well averted can be resisted.

Even in the most unprepossessing material, surprisingly much information can be gleaned if the necropsy is conscientious. The organs are often in far better condition than the external appearances would suggest, and toxicological and even histological examinations may be of considerable value in cases which look hopeless candidates for any scientific investigation. Other ancillary methods may be pressed into service with advantage, such as radiology and dental identification. Drugs may persist in the fluids and tissues for long periods - a case was recently reported where high concentrations of barbiturates were recovered after seven years' burial. Where estimations of alcohol concentrations are important, caution must be used in interpreting the results, as micro-organisms can both produce and destroy ethanol in dead tissues. Multiple sampling sites should be used and if the results of the analyses vary widely then correspondingly less reliance should be placed on the results. For example, in the
Moorgate Tube disaster, samples taken from the driver several days after his death showed up to a fourfold discrepancy from different sampling sites.

In summary, this helpful broadsheet emphasises the need for an investigation which should be at least as thorough in the decomposed body as in the more tolerable subjects placed before a medical examiner. This is all the more important because statistically the putrefied cadaver is more likely to have been the result of unnatural causes.

\footnotetext{
${ }^{1}$ Association of Clinical Pathologists, Broadsheet 91: Examination of a Decomposed Body. London, British Medical Association, 1979.
}

\section{Childhood urine infection in general practice}

Interest in urinary tract infection waxes and wanes, partly as a reflection of its current rating as a cause of renal damage. In the 1960 s urine infection was claimed to be the most important cause of renal damage and a preventable cause of renal failure. Now it is believed to be less important than glomerulonephritis, and there is some doubt whether current treatment can prevent renal damage. Nevertheless, there is agreement that urine infection causes much illness, unhappiness, and inconvenience, and that it is very common-particularly in childhood.

Screening studies have established that between $1 \%$ and $2 \%$ of girls at school have infected urine-csignificant bacteriuria." Kunin ${ }^{1}$ called this "asymptomatic bacteriuria," but the British workers who repeated his work drew attention to the fact that these children were not truly asymptomatic: they had minor symptoms including wetting and perineal discomfort, ${ }^{2}{ }^{3}$ and were "asymptomatic" only in so far as these symptoms had not caused them to consult a doctor.

Though most children with bacteriuria have some symptoms, most children with dysuria and frequency do not have an identifiable urinary tract infection. The work by J A Dickinson ( $p$ 1330) shows this well. In his general practice he studied nearly 3000 children over an 18 months' period, with reference to urinary tract infection and urinary symptoms. Only $18 \%$ of the children who presented with dysuria had infected urine. A less careful doctor could well prescribe unnecessary antibiotics and arrange needless further investigation. The reported association of upper respiratory tract infection and urethral symptoms is well recognised by those familiar with children.

Dickinson found an incidence of urinary tract infection in symptomatic children of between one and four per 1000 children per year. The figure is lower than in some surveys, possibly because of different criteria for "symptoms" or because of stricter bacteriological criteria, which achieved an excellent degree of reliability (though requiring a rather cumbersome culture method). More convenient semiquantitative culture methods are now available, and it is sad that they are used so infrequently in general practice. Dip-slides (such as Oxoid or Till-U-Test) and pad culture (such as Microstix) are reliable and easy methods. Their great advantage is that they can be done by the doctor (or patient) as soon as urine is passed. Their convenience cuts out the considerable errors that result from delay in transporting and testing urine. A few bacteriological laboratories have made dip-slides available to general practitioners, but elsewhere there have been 
complaints about the cost of the commercial slides having to be borne by the general practice. For this reason, and because of the inconvenience of collecting urine specimens, their use has been small. Greater use would allow prompt and effective treatment for many ill children whose urine infection has not been identified. It also would prevent unnecessary treatment of the many children who have urinary tract symptoms but no infection.

${ }^{1}$ Kunin, C, Zacha, E, and Paquin, A J, New England fournal of Medicine, 1962, 266, 1287.

2 Meadow, S R, White, R H R, and Johnston, N M, British Medicalfournal, $1969,3,81$.

3 Savage, D C L, et al, British Medical fournal, 1969, 3, 75.

\section{The Budd-Chiari syndrome}

Obstruction to the venous outflow from the liver is rare, but it produces a dramatic and often fatal illness. This was first described by Budd in 1845, when he was professor of medicine in London. ${ }^{1}$ The other half of the eponym came from a review of 13 cases by Chiari in $1899 .^{2}$ The syndrome is produced by occlusion of the major hepatic veins or the vena cava at that level; it should be distinguished from so-called veno-occlusive disease of the liver, usually seen in children, in which there is progressive obliteration of small intrahepatic veins.

The obstruction in the Budd-Chiari syndrome is caused by thrombus in the major hepatic veins or their ostia, and in cases running a chronic course thrombus may become organised into fibrous tissue. A variant described mainly from Japan is obstruction of the vena cava at the level of the hepatic venous ostia by a fibrous membrane or web $^{3}$ - presumably congenital, though the delay in clinical presentation is surprising.

The cause remains problematical. In a review of 164 cases Parker could find underlying causes in only $30 \%{ }^{4}$ These included polycythaemia rubra vera, leukaemias, trauma, hydatid disease, and invasion of hepatic veins by primary and secondary liver tumours. Paroxysmal nocturnal haemoglobinuria and, more recently, oestrogen-containing oral contraceptive pills should now be $\operatorname{added}^{56}$ to this list. Men and women are equally affected, and most patients are in their $20 \mathrm{~s}$ or $30 \mathrm{~s}$. The clinical picture is dominated by ascites, enlargement of the liver, and abdominal pain. In about a fifth of patients the illness is fulminant with a rapid downhill course leading to death in liver failure within a few weeks. More commonly symptoms have been present for two to six months by the time the patient is first seen, and this more insidious onset may reflect either gradual occlusion of the hepatic venous outflow or a more efficient collateral circulation.

Clinical diagnosis is often difficult and demands a high index of suspicion. The most common differential diagnosis is cirrhosis with portal hypertension, but congestive cardiac failure and constrictive pericarditis need to be considered. The results of biochemical tests of liver function are usually abnormal, and about one-third of patients are jaundiced. ${ }^{4}$ Percutaneous needle biopsy specimens of the liver will show hepatic venous congestion with areas of centrilobular necrosis and haemorrhage. To distinguish the Budd-Chiari syndrome from other causes of venous congestion of the liver ${ }^{7}$ - important if surgery is planned-the inferior vena cava and hepatic veins need to be delineated. Swelling of the liver produces characteristic narrowing of the cava just below the diaphragm. ${ }^{7}$
At least one major hepatic vein can usually be catheterised at venography, when injection of contrast medium in the wedged position will show a typical spider web network of small venous collaterals. When an experienced operator fails to cannulate the hepatic vein and there is no reflux of contrast into the hepatic veins during a Valsalva manoeuvre the balance of probability is strongly in favour of occlusion of the hepatic vein.

Radioisotope scintiscanning may show a central "hot spot" as a result of sparing of the venous drainage of the caudate lobe through small branches separate from the main right and left hepatic veins. ${ }^{8}$ Nevertheless, the findings from the liver scan are not always diagnostic, and there may be patchy liver uptake combined with large extrahepatic uptake in the spleen and bone marrow, an appearance indistinguishable from cirrhosis. ${ }^{9} 10$

Patients who present with a fulminant illness die rapidly in hepatic coma. Those with a more gradual course may be improved temporarily by general medical measures, but many later succumb to bleeding from oesophageal varices. ${ }^{11}$ The overall two-year survival is less than $10 \%$. Diuretics and salt restriction are the cornerstones of medical management, combined with treatment of any underlying cause such as polycythaemia rubra vera. Anticoagulants and fibrinolytic agents have been used, ${ }^{12}$ but the results have been disappointing.

Various aggressive approaches have been tried in an attempt to prevent the development of portal hypertension and deterioration in liver function. Membranous obstruction to the inferior vena cava may be corrected by transatrial membranotomy. ${ }^{1314}$ Portal decompression by shunt surgery is an attractive concept, but the results have been mostly disappointing-that is, until a recent report from Orloff and Johansen. ${ }^{10}$ Using side-to-side portacaval shunts, they achieved complete resolution of ascites, disappearance of hepatosplenomegaly, and biochemical recovery in five of six patients, who have now been followed for between eight months and seven years. Preoperative hepatic venography and splenic arteriography with late films are essential to confirm patency of the vena cava and the portal vein. In patients in whom the inferior vena cava is occluded mesoatrial grafts ${ }^{10}$ and orthotopic transplantation ${ }^{15}$ have been tried with occasional success. The LeVeen peritoneojugular shunt may produce dramatic resolution of ascites, ${ }^{16}$ but as it does not decompress the congested liver there is no reason to expect improvement in hepatic function or portal hypertension; it should be reserved for patients in whom more definitive surgery is not feasible. Thus we await really effective treatment for patients with this syndrome.

1 Budd, G, On Disease of the Liver, p 147. London, Churchill, 1845.

${ }^{2}$ Chiari, H, Beiträge zur Pathologischen Anatomie und zur Allgemeinen Pathologie, 1899, 26, 1.

3 Takeuchi, J, et al, American fournal of Medicine, 1971, 51, 11.

4 Parker, R G F, Medicine (Baltimore), 1959, 38, 369.

5 Sterup, K, and Mosbech, J, British Medical fournal, 1967, 4, 660.

- Wu, S-M, Spurny, O M, and Klotz, A P, American fournal of Digestive Diseases, 1977, 22, 623.

${ }^{7}$ Kreel, L, Freston, J W, and Clain, D, British Fournal of Radiology, 1967, 40, 755 .

8 Tavill, A S, et al, Gastroenterology, 1975, 68, 509.

${ }^{9}$ Chaudhuri, T K, et al, fournal of the American Medical Association, 1972, 221, 506.

10 Orloff, M J, and Johansen, K H, Annals of Surgery, 1978, 188, 494.

1 Schramek, A, et al, Annals of Surgery, 1974, 180, 368.

12 Warren, R L, et al, Gastroenterology, 1972, 62, 200.

${ }^{13}$ Kimura, C, et al, fournal of Cardiovascular Surgery, 1962, 3, 393.

14 Kimura, C, et al, Surgery, 1972, 72, 551.

15 Putnam, C W, et al, fournal of the American Medical Association, 1976, 236, 1142.

16 LeVeen, H H, et al, Annals of Surgery, 1976, 184, 574. 